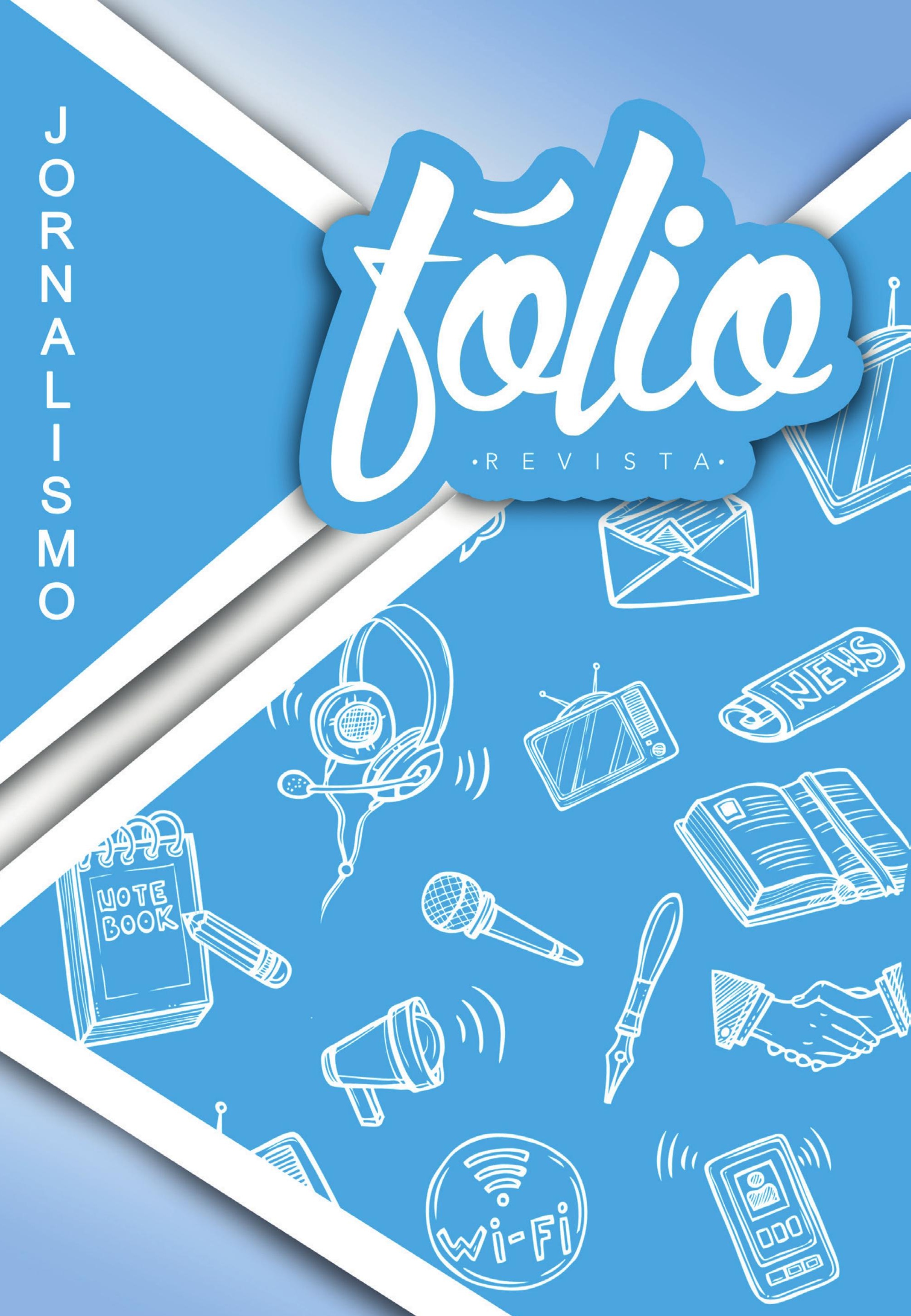




\section{O metadocumentário a partir da teoria enativa: um estudo sobre cognição e audiovisual}

\section{The metadocumentary from the enative theory: a study on cognition and audiovisual}

\section{Luciana Kraemer ${ }^{1}$}

\section{Resumo}

A evolução das Tecnologias da Informação e Comunicação (TICs) tornou o consumo e a produção audiovisual cada vez mais acessíveis, dando mais relevância à pesquisa sobre os aspectos cognitivos ligados ao cinema. Neste artigo, utilizamos a teoria enativa (Varela/SD; Varela, Thompson, Rosch, 2003; Thompson, 2007), para analisar o metadocumentário - ação de colocar o filme no filme. A hipótese é de que o mesmo nos permite ver a cognição como ação que coemerge da relação entre mente, corpo e meio. A partir da cartografia, tomamos como experiência dois anos de disciplinas de produção audiovisual para estudantes de jornalismo. A partir de trechos dos filmes produzidos por eles, procuramos mostrar que esta produção documental dá visibilidade ao conhecimento como autopoiéses envolvendo acoplamentos com agentes humanos e não humanos.

Palavras chave: Documentário. Audiovisual. Enação. Cognição. Metadocumentário.

\section{Abstract}

The evolution of Information and Communication Technologies (ICTs) has made consumption and audiovisual production increasingly accessible, giving more relevance to research on the cognitive aspects of cinema. In this article, we use the enactive theory (Varela / SD; Varela, Thompson, Rosch, 2003; Thompson, 2007) to analyze the metadocumentary - action of putting the film in the film. The hypothesis is that it allows us to see cognition as an action that comes from the relationship between mind, body and environment. From the cartography, we take as experience two years of audiovisual production material for journalism students. From excerpts from the films produced by them, we try to show that this documentary production gives visibility to knowledge as autopoieses involving couplings with human and nonhuman agents.

Keywords: Documentary. Audiovisual. Enaction. Cognition. Metadocumentary.

1 Doutoranda em Informática na Educação (UFRGS), professora dos cursos de Jornalismo e Cinema (Unisinos). E-mail: luciana.kraemer@ gmail.com 


\section{Introdução}

ste artigo está inserido numa pesquisa de doutorado e abrange ao menos três campos do conhecimento, a cognição, a memória e o cinema. Entendemos relevante distinguir que o documentário tem se constituído ao longo da história não apenas como um modo, mas também como um método científico para produzir conhecimento sobre o mundo a partir de agenciamentos maquínicos. $\bigcirc$ filme etnográfico, segundo Rouch (2015), nasceu antes mesmo do cinema, e foi guiado por avanços técnicos: a película flexível e móvel criada por Eastman ${ }^{2}$ e a espingarda cronofotográfica de Marey ${ }^{3}$ possibilitaram o estudo científico da natureza em movimento, do vôo dos pássaros à corrida do homem. Mesmo que não fosse um cientista, Robert Flaherty e suas explorações produziram Nanook, o Esquimó (Nannok of the North), em 1922, um arquivo único sobre o experienciar da vida da tribo itivimut, no ártico do Canadá. Até hoje um marco do cinema documental. E que conhecimento é este produzido a partir de uma máquina audiovisual? Compreendemos que o conhecimento produzido a partir documentário não é representacionista (cognitivismo clássico), pois não representa um tema a partir de um mundo preexistente. De outra forma teríamos que concordar que o mundo nos oferece inputs ou instruções, e que através dos processamentos mentais, são criadas representações do conhecimento. A nossa hipótese é que o filme atua, produzindo sujeitos e mundos a partir de histórias de acoplamentos que envolvem o documentarista, os personagens (entrevistados) e o meio em que todos estão envolvidos, incluindo agenciamentos humanos e não humanos (máquinas e redes). É a Teoria Enativa (VARELA; THOMPSON; ROSCH, 2003) que nos dá suporte para esta perspectiva. A corrente da enação se contrapõe às teorias psicológicas de modelo representacionista, nos possibilitando pensar nos processos cognitivos como uma experiência que integra a biologia sem, en-

2 George Eastman (1854-1933)

3 Étienne-Jules Marey (1830-1904) tretanto, se reduzir a ela. Somos, como seres vivos, o que a filogenia da nossa espécie tem produzido há milhares de anos e, ao mesmo tempo, somos o que estamos produzindo ao longo da nossa existência, modificando e sendo modificados pelo mundo, em uma circularidade que compromete e indissocia ambos, sujeitos e mundos. Distingue-se, desta forma, adaptação de acoplamento. Adaptar-se remete a processos interativos que pressupõem a capacidade emocional de lidar e sobreviver no ambiente, não levando em conta as modificações do meio após a nossa presença. O acoplamento estrutural (MATURANA e VARELA, 2001) ocorre quando temos perturbações recorrentes e recursivas gerando coproduções. Assim, sujeitos, objetos e mundos são produzidos no ato mesmo de conhecer, a partir do processo que os cria, na circularidade gerada pelas interações que determinam as circunstâncias e a dinâmica dos caminhos trilhados. Humberto Maturana e Francisco Varela afirmam que a vida consiste em um sistema que é autopoiético, de organização circular, no qual a circularidade conserva e produz o próprio sistema. A biologia do conhecer implicando uma filogênese e ontogênese da espécie nos faz pensar no conhecimento menos como substantivo e mais como verbo: "conhecer é viver e viver é conhecer". Conhecer é uma ação que dura no tempo e não pode ser vista como desincorporada, ou seja, pensada em uma atuação que exclua o corpo. Toda experiência cognitiva passa por ter um corpo com capacidades sensório-motoras envolvidas em domínios diversos, com diferentes contextos. Pensar no conhecimento como corporificado nos permite levar em conta também a dimensão coletiva da atuação, pois é com o corpo que nos fazemos presentes no mundo.

A partir da cartografia, tomamos como experiência de quatro semestres anos de disciplinas de produção audiovisual no curso de Bacharelado em Jornalismo (IPA). No período, os estudantes tinham como objetivo produzir metadocumentários. A partir de trechos dos filmes produzidos por eles, procuramos mostrar que esta produção documental dá visibilidade ao conhecimento como enação.

$\bigcirc$ presente estudo está dividido em 5 seções: 1) introdução 2) conceitos de metadocumentário e metalinguagem 3) a hipótese de metadocumentário 
como experiência enativa 4) cenas de um metadocumentário 5) conclusões. Na seção que vem a seguir trazemos algumas considerações teóricas sobre o fazer metadocumental para depois seguir avançando na perspectiva enativa associada a este fazer.

\section{Entendimentos sobre metadocumentário e metalinguagem}

A tradição teórica documental fez algumas proposições explicativas para discutir as produções de sentido abertas com a colocação do filme dentro do filme. Nichols (2005) e Machado (2011), por exemplo, tratam o documentário como uma peça discursiva, uma enunciação, em que são colocadaso em jogo as relações dialógicas entre enunciador/emissor (cineasta) e enunciador/emissor (personagem) e receptor/enunciatário (espectador). Na tipologia de Nichols, o documentário "reflexivo"4 é um subgênero, o formato de um discurso que tem como marca ético-estética a reflexão sobre como se está filmando o que está sendo filmado, se constrói problematizando o processo de criação. Por adotar uma visão representacionista do documentário, mas também construcionista, Nichols vai falar que esste tipo de documentário desnuda os problemas de representação do outro, os caminhos trilhados pelo diretor para a montagem das cenas, as dúvidas e as certezas acumuladas:

O documentário reflexivo é o modo de representação mais consciente de si mesmo e aquele que mais se questiona. $O$ acesso realista ao mundo, a capacidade de proporcionar indícios convincentes, a possibilidade de prova incontestável, o vínculo indexador e solene entre imagem indexadora e o que ela representa - todas essas ideias passam a ser suspeitas. (NICHOLS, 2005, p. 166).

Machado (2011) vai na mesma linha quando diz que o metadocumentário é "o tipo mais cruel"

4 Os outros subgêneros são: poético, o expositivo, o observativo, o participativo e o performático. do documentário, por denunciar a forma com que os cineastas se apropriam da palavra do outro a fim de confirmarem argumentos, teses, versões do mundo compartilhado. O fazer fílmico é objeto de observação do realizador, que por sua vez é objeto de observação do espectador, numa circularidade que está centrada no mundo experiencial dos realizadores da obra e de todos os que nela se envolvem: "de fato, o seu tema básico é sempre o próprio documentário, o mundo, as razões que ele alega, as instituições que o promovem e os fins a que se destina" (MACHADO, 2011, p. 13).

Já Andrade (1999, p. 21) entende a metalinguagem como um recurso que tem função na linguagem, e estuda seu uso no cinema sem se deter nos aspectos de gênero, apesar de trabalhar basicamente com a ficção. A análise feita pela autora revela dois empregos frequentes ao longo do século XX: quando o filme fala sobre o cinema e quando fala sobre si mesmo. No primeiro, a metalinguagem é "elemento narrativo temático em que a autoreferência implica reconhecimento ou identificação por parte do público". Um exemplo seria o filme Corrida de Aautomóveis para Mmeninos (dir. Henry Lehrman, 1914) quando Chaplin estreia do personagem Carlitos. Na obra, o recurso serve para criar no público a ideia de participação, e o espectador obtém informações sobre o ritual cinematográfico. Em algumas cenas Carlitos olha para a câmera numa alusão de diálogo com o espectador, algo como "olhem só o que vou fazer agora". Em outros momentos, se coloca entre a câmera e a pista, impedindo que operadores realizem a gravação da corrida. Já quando o filme fala sobre si, a metalinguagem não é apenas um elemento narrativo, mas uma força articuladora essencial para que a trama se desenvolva.

Foi a partir dos anos 1950, com a maior concorrência da $T V$, que o cinema passouaria a ser autocriticar, questionando a lógica de produção industrial que objetivava seus ganhos. A autorreflexão também cabe nesste recurso que explora a crise de estagnação criativa de um diretor de cinema pressionado para gravar um filme. É o que ocorre com Guido Anselmi - supostamente alterego de Frederico Fellini -, diretor personagem de Oito e Meio (dir. Federico Fellini, 1963).

O entendimento de Andrade (1999) é seme- 
Ihante ao de Chalub (2005) por dialogar com a linguística. A segunda entende que a metalinguagem tem função denotativa e conotativa nas artes, pois opera com o código na tentativa de retraduzi-lo. É como a explicação da explicação, linguagem falando da linguagem. Uma maneira de ser conhecendo o funcionamento do seu ser, uma espécie de episteme, diz a autora.

A ideia da metalinguagem como função de linguagem tem raiz no linguista Roman Jakobson. Para o russo, um dos modos de uso da língua com fins de interação e compreensão sobre o mundo se dá pela metalinguagem ${ }^{5}$, que tem como função primária traduzir a linguagem-objeto, entendida como o código referente. Para nos movimentarmos na linguagem é necessário que saibamos compreender seus códigos, entender como se combinam (sua gramática), e ainda os traduzir a partir de nossa vivência na língua. As operações metalinguísticas, segundo o autor, são complementares a nossa experiência e têem função reorganizacional, de recodificação. Para JakKobson (2001, p. 47), as operações metalinguísticas são essenciais tanto para a aquisição da linguagem como para o seu funcionamento: "A interpretação de um signo linguístico por meio de outros signos da mesma língua sob certo aspecto homogêneo, é uma operação metalinguística que desempenha papel essencial na aprendizagem pela criança".

Apesar da teoria de Jakobson estar inserida num certo pensamento funcionalista e que vê a linguagem a partir de estruturas delimitadas, acreditamos que ela propõe um diálogo com a enação, na medida em que convida a pensar a metalinguagem como estratégia para uma ação dos sujeitos na linguagem a partir de uma ontologia que se dá por esta atuação. O pensamento será desenvolvido a seguir.

\section{A hipótese de metadocumentário como experiência enativa}

A ação de colocar o filme no filme produz uma

5 As outras funções seriam referencial, emotiva, conativa, fática e poética. vigilância, uma dobra no operar o cinema. $O$ metadocumentário coloca em movimento o próprio processo cognitivo, promovendo um saber-fazer e um dizer sobre este fazer, que é um outro saber, pois, como nos diz Maturana (1997 p. 246), qualquer explicação sobre algum aspecto da práxis do viver é secundária à práxis do viver, mesmo que as explicações sejam também experiências a serem explicadas. Ou seja, o explicar é uma experiência cognitiva diferente do conhecer, mesmo que este seja determinado peloa primeiroa. Neste estudo, conforme já abordado em outro texto nosso (Gomes eE Kraemer, (2017) a metalinguagem é compreendida como um recurso potente para questionar uma visão representacionista do conhecimento, na medida em que pois evidencia os domínios comportamentais que concorrem para estabelecer os critérios de validação que atuam de maneira circular na formação da conduta, no caso, a própria filmagem. Nesse sentido, é uma prática autopoiética que se produz na direção de um dos aforismos de Maturana e Varela (2001, p. 31): "tudo o que é dito é dito por alguém".

Deleuze (2013) dispensa um espaço na sua obra sobre a imagem-tempo para pensar no regime em que se inserem os filmes que se refletem no filme (metalinguagem). Trabalhando com os conceitos de atual e virtual para compreender as possibilidades do real, o filósofo vai entender que neste regime, o que tem potência de ser (virtual) e o que se atualiza como ser, se apresentam no regime cristalino de imagens em que a lógica é a da indiscernibilidade:

O germe e o espelho são mais uma vez retomados, um na obra se fazendo, o outro na obra refletida na obra. Estes dois temas, que atravessam todas as outras artes, iriam afetar também o cinema. Ora é o filme que se reflete numa numa peça de teatro, num espetáculo, num quadro ou melhor, num filme no interior do filme; ora é o filme que se toma por objeto no processo de sua constituição ou de seu fracasso em se constituir. (DELEUZE, 2013 p.96)

Deleuze não cria uma tipologia para diferenciar as formas metalinguísticas, e sequer usa a expressão meta para se referir a este tipo de obra. 
Mas ao citar a imagem em germe deixa claro que se trata de uma imagem que se revela na ação do seu próprio fazer, e se nutre dos seus fracassos e dos seus limites. Para Deleuze, a ação meta expõe uma reflexão crítica sobre o modo de ser do cinema, em alguns casos está ligada à morte do cinema ação ou do cinema movimento. É um procedimento, um modo de composição da imagem cristal.

Tomamos o entendimento de Deleuze para avançar na perspectiva do conhecimento como enação. O filme que fala de si propõe um olhar circular que se centra no processo, na ação, o caráter enativo se mostra a partir das ações que tornam visíveis as condições de cognição possibilitadas pelos acoplamentos humanos e não humanos. A ação de por o filme no filme dá visibilidade a desestabilização das formas constituídas que estão fixadas nas imagens-lembranças, nos arquivos, na própria tradição representacionista que percebe o documentário como um estoque de memória do outro e do mundo entregue numa caixa sedimentada. Expor a imagem em germe, é revelar o que a imagem guarda em potência, ao mesmo tempo em que se atualiza como um modo de ser documentário possível. Mais do que expor fracassos e limites (e também há mérito ético-estético nessa exposição) revela um processo de conhecimento que não é transcendente, se dá na ontologia do fazer documental a partir de uma autoprodução no interior do sistema, e não como (re) presentação de um conhecimento externo. A realização documental cria um mundo a partir de um campo de força em que se produzem acoplamentos humanos e não humanos, em que o conhecimento coemerge destas condições.

Deleuze (2013) entende que ser necessária uma justificativa para essa escolha (colocar o filme dentro filme), para que a ação não configure apenas a confissão de uma espécie de culpa pela suposta incapacidade de cercar o objeto. A justificativa para essa escolha pode dizer também sobre um compromisso ético-estético de discutir o quão complexo é produzir regimes de verdades numa peça audiovisual. O metadocumentário, que ao longo dos nossos estudos já foi compreendido como linguagem, hoje percebemos como uma ação que mobiliza cognições, e é um recurso para desencaixar as estruturas de pensamentos em blocos, que supostamente guardariam a memória, como o que já passou, em arquivo.

\section{Cenas de um metadocumentário}

Conforme havia explicado na introdução, entendemos que o documentário é um modo de produção de mundos, criação de realidades. Compreendemos também a pesquisa como um processo que intervém fazendo coemergir o objeto, o sujeito e o conhecimento (PASSOS E BARROS, 2015). As teorias não representacionistas da cognição, como a teoria biológica do conhecer ou Teoria Autopoiética (Maturana e Varela, 2001) e a Teoria Enativa se orientam pela perspectiva de que o domínio cognitivo não é predeterminado, nem representado, mas efetuado pela atuação, pela experiência que se constitui no ato de conhecer. O ponto de apoio, ainda citando Passos e Barros (2015), é a experiência de um saber-fazer, que emerge do fazer e passa para um fazer-saber, que é outra experiência, a experiência do saber.

A cartografia é o método da pesquisa que visa a acompanhar esses processos que estão cercados de implicações, conscientes e inconscientes. Nesta seção, avançamos os circuitos da memória - uma das bagagens do cartógrafo - segundo Fischer (2008), e exploramos uma série de experiências que não estavam sendo acessadas, talvez porque, como entende Bergson (2010), não haviam sido chamadas à utilidade. As imagens-lembranças nos trazem referências acumuladas desde 2012, quando iniciamos o trabalho com o metadocumentário. As cenas a seguir se referem a duas formas de experienciar a metalinguagem no cinema, conforme Andrade (1999). Uma delas, quando o filme fala sobre si e quando o filme fala sobre o cinema.

\section{Um filme que fala sobre si}

Um grupo de alunos (com faixa etária em torno de 20 anos) conversa com a professora da disciplina de Introdução ao Documentário. Os estu- 
dantes estão visivelmente insatisfeitos, contrariados com o rumo que o doc produzido por eles estava tomando. $\bigcirc$ argumento ${ }^{6}$ era relevante: mostrar como os imigrantes japoneses que viviam em Porto Alegre seguiam mantendo os hábitos culturais de seu país de origem (alimentação, trabaIho, entretenimento). A pesquisa tinha sido bem realizada pelos alunos, a ideia era original, mas o que parecia adequado no projeto encaminhado, não se concretizava na execução. Como em quase todo o processo de produção documental, é especialmente nas diferentes configurações do campo de trabalho (biológicos, psicológicos, culturais) que os processos de aprendizagem parecem (ou não) fazer mais sentido. Uma dificuldade que não tinha sido prevista (porque não experienciada anteriormente) era a comunicação com as famílias japonesas, que pouco falavam português. Outra, era a falta de mais famílias que cumprissem o que estava no projeto inicial do documentário (ter nascido no Japão). E hHavia também os problemas de ordem mais concreta, como os parcos recursos previstos para os deslocamentos. Resultado: o material de que eles dispunham não seria suficiente para a produção de um doc de 15 minutos. O que fazer?

Figura 1 - Cena com os estudantes

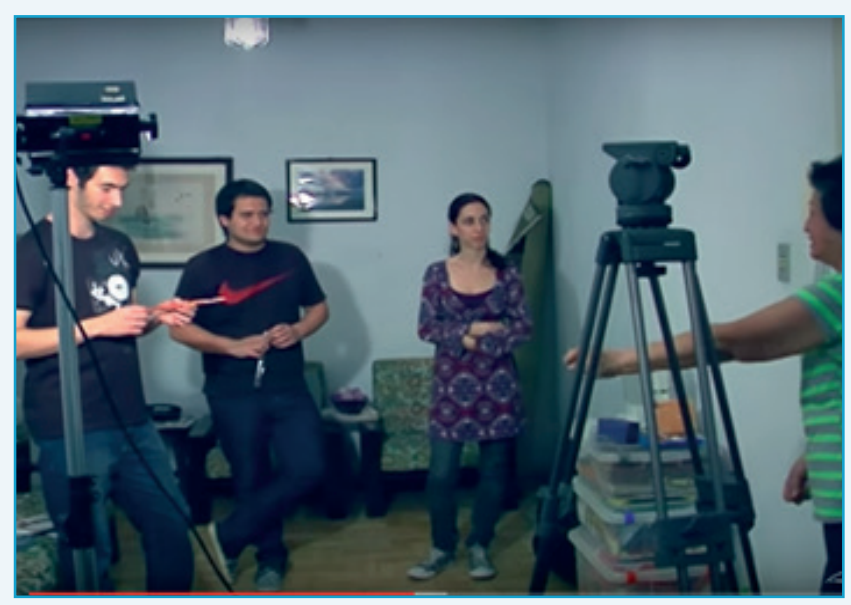

Fonte: SEM_ROTEIRO.DOC (2012). Printscreen.

6 Também conhecidoa como sinopse, argumento é um procedimento inscrito no momento de pré-produção do documentário. É a etapa seguinte à pesquisa inicial sobre o tema a ser trabalhado no documentário. É um resumo da história (PUCCINI, 2012).
Já inspirados no documentário Santiago (2007), nós, professores, propusemos aos alunos colocar o filme dentro do filme, usar um recurso meta. Naquele momento, achávamos que a estratégia daria a chance deles a chance de contarem uma história no curso do acontecer da história, a história de fazer um filme "que não estava dando certo".

Os professores então passam a assistir outras cenas selecionadas para entrarem no filme, como as cenas gravadas dos estudantes captando imagem (estilo making-off), as imagens das imagens das entrevistas com os japoneses, além de uma seleção de trechos de filmes antigos e memes ${ }^{7}$ do Youtube para compor as cenas do doc. Era uma nova lógica a ser experienciada, utilizar o recurso da ação sobre a ação. Para a produção do doc. os estudantes contavam com um laboratório de TV equipado com câmeras profissionais e semiprofissionais, microfones diversos para a captação de som, pcscomputadores, i-Mmacs para a montagem, e técnicos que colaboravam com o processo de produção. $\bigcirc$ filme acabou sendo batizado como Sem_roteiro.doc (2012) ${ }^{8}$.

Figura 2 - Cena inicial de Sem_roteiro.doc

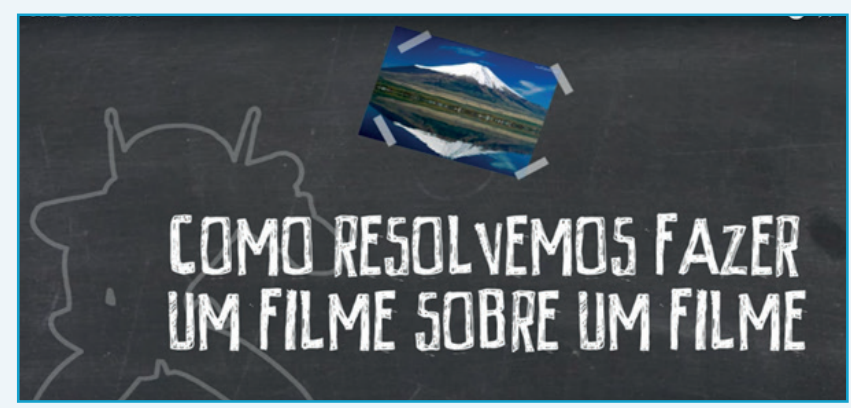

Fonte: SEM_ROTEIRO.DOC (2012). Printscreen

No lugar de uma maneira um formato linear, o Sem_roteiro.doc (2012) vai se desnudando em numa perspectiva de interface, com as cenas se abrindo para as novas conexões que vão surgindo a partir não das pré-escolhas, mas das trilhas

\footnotetext{
7 Os memes são imagens, vídeos, frases, entre outros, que se viralizam por fontes de informação na web.

8 https://www.youtube.com/watch?v=|3SnzPA1PpA Disponível em: <https://youtu.be//3SnzPA1PpA>. Acesso em: 12 nov. 2017
} 
descobertas no decorrer dos próprios caminhos, atualizando algumas questões e deixando outras em devir. As questões, dúvidas estéticas que até então ficavam restritas às conversas off the record (entendidas até então como sendo de trabalho) passaram a ser filmadas para depois serem compartilhadas com espectador: "Como vamos começar o filme? Como lidar com um personagem (entrevistado) simpático, divertido, mas que quase não fala português? " Perguntavam eles. As referências de uma estética de vídeos da web, em meio às cenas, revelavam o imaginado e o criado no mesmo plano. No nosso entender, nestas imagens cristal em germe (Deleuze, 2013), que é ao mesmo tempo a imagem refletida, o espectador vê a imagem que é virtual em relação ao que se pretende ser, e atual em relação à como se realiza produzindo diferença. $\bigcirc$ mise-en-scène da a ver que as subjetivações incluem os agenciamentos maquínicos. A montagem é uma operação que está longe de ser puramente técnica, há uma ética, uma estética, uma tecnologia que produz pensar e que demanda cognições constituídas ao mesmo tempo que convoca outras virtualizadas.

O que era para ser a história dos japoneses que viviam em Porto Alegre se transformou na história dos estudantes de jornalismo que queriam fazer um documentário sobre a história dos japoneses que viviam em Porto Alegre. No processo, se produziu uma diferença em relação àa forma cinema usual no meio universitário. O filme acabou sendo reconhecido pelo campo?. Ganhou dois prêmios, um deles nacional.

Figura 3 - Cena de Sem_Roteiro.doc com entrevistados e professores

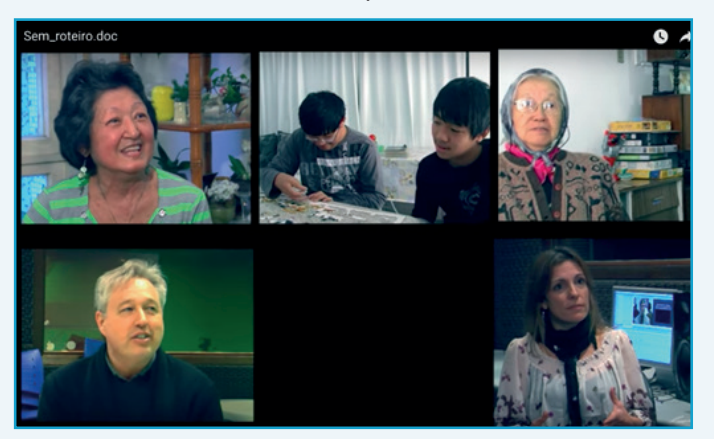

9 Prêmio de Melhor Vídeo na Categoria de Cinema e Áudio Visual Experimental na Mostra Competitiva do $25^{\circ}$ SET Universitário e Produção Laboratorial em Videojornalismo no Intercom Sul 2013.

\section{Um filme que fala sobre o cinema}

Apesar de modesto, com pouca tradição no ensino de jornalismo, o curso de bacharelado em Jornalismo do IPA (fundado em 2005) logo passou a ganhar visibilidade por produzir documentários de qualidade, vencedores de mostras e festivais. Uma história de relações sociais e de aprendizagem vetorizadas pelos usos e apropriações do ferramental em que se produziam estudantes e professores apaixonados por cinema e seus objetos simbólicos (filmes). Impossível determinar o que impulsionava mais o conhecimento sobre o fazer. A experiência e o saber teórico dos professores, o grupo técnico que dava suporte ao trabalho dos alunos (cinegrafistas e editores), o maquinário à disposição (um laboratório completo para o ensino e aprendizagem do audiovisual). Muitas vezes nos perguntamos isso ao longo do curso e, quando a tecnologia empregada começou a não dar mais conta das necessidades - câmeras analógicas sem profundidade de campo, microfones que não captavam adequadamente em ambientes externos, falta de memória e processadores lentos nos desktops utilizados para editar os materiais identificamos que o conhecimento e a vontade do corpo docente e discente não eram suficientes. Não há dissociação entre os sujeitos e meios para a produção, não é uma questão de mediação, e sim de agenciamentos, acoplamentos.

A partir de 2013, foi possível perceber uma mudança importante em direção à digitalização dos meios para a produção documental no curso, possibilitando novas experiências do operar cinema a partir dos acoplamentos envolvendo estudantes, técnicos, professores e novas máquinas. A aquisição de câmeras fotográficas (DSLR) Canons (7 D) utilizadas no mercado publicitário e de cinema, além de microfones e também novos i-Mmacs para o trabalho de pós-produção (montagem), $O$ primeiro doc produzido a partir da renovação do laboratório foi o filme "Mestres (dir. Tiago Fernandes e Marcelo Noms, 2013)10", sobre o Campeo-

10 https://www.youtube.com/watch?v=7jPdh5ofARQ\&t=70s 
nato Mundial de Atletismo Master (WMA 2013), pela primeira vez realizado na América Latina, e que havia trazido mais de 4.000 atletas de 80 países para Porto Alegre. Ao longo do processo de captação (vídeo, áudio), foi possível perceber o quanto os meios ampliavam as possibilidades ético-estéticas do filme, proporcionando a obtenção de um nível de qualidade percebida semelhante aos produtos que circulam na web.

Figura 4 - Cena do documentário Mestres

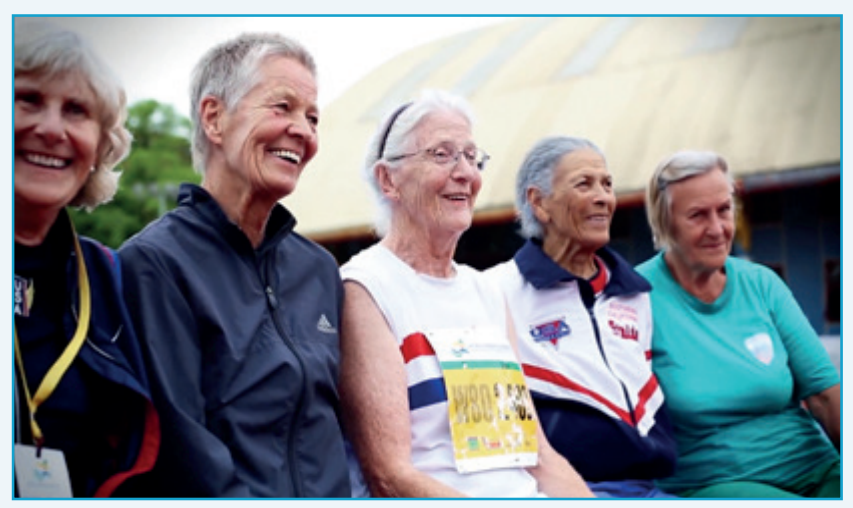

Fonte: MESTRES (2013). Printscreen.

Figura 5 - Metadocumetário Da Lua à Ladeira

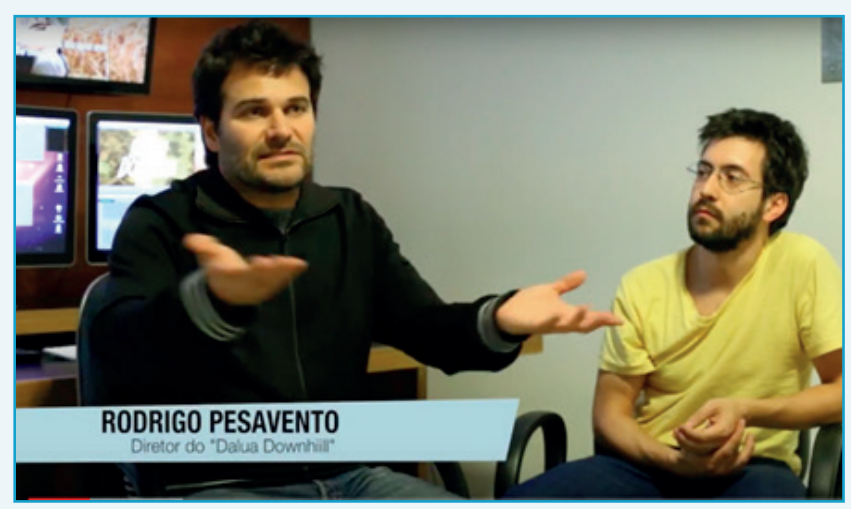

Fonte: Da Lua à Ladeira (2014) $)^{11}$. Printscreen

Com as novas possibilidades, passamos a incorporar mais o uso dos equipamentos de vídeo nas práticas de ensino e aprendizagem das atividades acadêmicas de audiovisual. Em pelo menos dois semestres sugerimos que os alunos tivessem a experiência documental a partir da metalingua-

11 Disponivel em: <https://www.youtube.com/ watch?v=0pVUketmuM8>. Acesso em: 12 nov. 2017 gem. O desafio era produzir vídeos curtos (5 minutos) em que poderíamos assistir um doc sobre um doc escolhido por eles, algo como o filme do filme. O exercício tinha como intenção consciente que o recurso da metalinguagem fosse um elemento narrativo temático (ANDRADE, 1999) do doc, uma das formas recorrentes encontradas pela pesquisadora para o uso da metalinguagem no cinema. Havia também, de nossa parte uma preocupação de ordem funcionalista.

Como já apontado na seção 2 deste trabalho, para linguistas como Jakobson (2001), as operações metalinguísticas são essenciais tanto para a aquisição da linguagem como para o seu funcionamento. Naquele momento, meu objetivo era que eles os alunos operassem na linguagem traduzindo a linguagem-objeto, no caso, o doc escoIhido para ser estudado. Usando uma expressão comum, mais ou menos como making-off que se ocupa do processo de produção tanto do doc escolhido, como do que estava em curso.

Figura 6 - Metadocumentário Consertando Estrelas

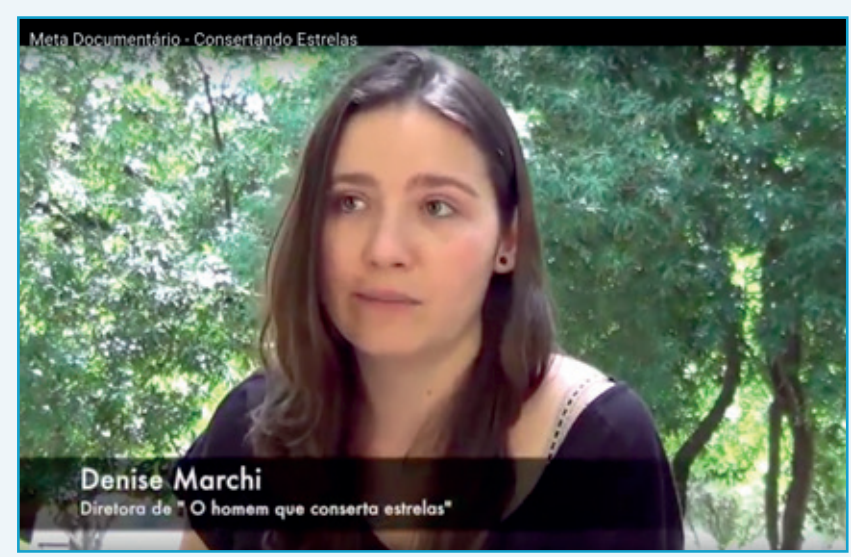

Fonte: Consertando Estrelas ${ }^{12}$ (2014). Printscreen

A diferença em relação ao Sem Sem_roteiro. doc (2012), é que esses não pressupunham dobras sobre a produção em curso, não se colocava como questão o dizer-saber-fazer, que mobiliza mais linhas de força do que o fazer que se mostra saber. $\bigcirc$ trabalho se constituía em aprender fa-

12 Disponível em: <https://www.youtube.com/ watch? $v=n J e D a M t L g t A \& t>$. Acesso em 12 nov. 2017.=131s 
zendo uma escuta do outro que fala sobre como aprendeu. Certamente que revela uma ação cognitiva do outro que produziu, mas pouco diz sobre a experiência do realizador da obra em curso. Neste caso, as dobras, no lugar de se produzirem a partir de si, são produzidas e visibilizadas a partir do outro.

De qualquer maneira, ambos os modos metalinguísticos, o filme que fala de si, e o filme que fala do cinema, nos possibilitam pensar na cognição como experiência que coemerge levando em conta não apenas o cérebro, mas mente, corpo e meio.

\section{Conclusão}

Compreendemos o documentário como uma tecnologia de informação, máquina simbólica acessível ao nosso domínio cognitivo, que pode oferecer a chance de criar novos problemas, levar a novas formas de estar, de se relacionar com o tempo e o espaço. Ao longo do artigo reunimos pistas para pensar como a prática fílmica documental compreendida como metadocumentário - ação de colocar o filme no filme - se coaduna com a perspectiva enativa do conheci- mento, ou seja, em que a cognição depende de ação incoporada de mente, corpo e meio (Varela/SD; Varela, Thompson, Rosch, 2003; Thompson, 2007). Tendo como metodologia a cartografia, tomamos como objeto empírico a experiência de quatro semestres de disciplinas ligadas à produção audiovisual no curso de Jornalismo. A análise do trabalho desenvolvido com e pelos estudantes teve como objetivo identificar pelo menos duas formas de promover a metalinguagem, a partir do filme que fala sobre si e do filme que fala sobre cinema. Ambos os modos de colocar o filme no filme nos permitem pensar na cognição a partir de uma perspectiva não representacionista, ou seja, não tomando o conhecimento como algo externo aos sujeitos, algo que se dá por instrução, de fora para dentro. A hipótese defendida no artigo é de que o metadocumentário dá visibilidade à cognição como ação autopoiética a partir de acoplamentos que se dão entre mente, corpo e meio. Importante lembrar que este artigo se insere numa pesquisa de doutorado que segue em curso. Neste sentido, compreendemos que ainda há um percurso a ser seguido no sentido de ampliar tanto as análises sobre as conclusões acerca da hipótese defendida.

\section{Referências}

ANDRADE, A. L. O filme dentro do filme: a metalinguagem no cinema. Belo Horizonte: UFMG, 1999.

BERGSON, H. Matéria e memória: ensaio sobre a relação do corpo com o espírito. 4. ed. São Paulo: WMF Martins Fontes, 2010.

CHALHUB, S. A metalinguagem. São Paulo: Ática, 2005. CORRIDA de Automóveis para Meninos. Direção: Henry Lehrman. Estados Unidos: Keystone, 1914. (6min).

DELEUZE, G. A imagem-tempo, Cinema 2. São Paulo: Brasiliense, 2013. 1. ed. 1990.

JAKOBSON, R. Linguística e comunicação. 9. ed. São Paulo: Cultrix, 2001.

FISCHER, M.E. O cartógrafo e sua bagagem. In: MALDONADO, A.E; BONIN, J.A; ROSÁRIO, N.M. Perspectivas Metodológicas em comunicação: desafios da prática investigativa. João Pessoa: Editora Universitária da UFPB, 2008. p. 221 a 228. 
GOMES, R.; KRAEMER, L. O metadocumentário como tecnologia de problematização de si e do mundo. In: MARASCHIN, C.; KROEFF R. F. S.; GAVILLON, P. G. (Orgs.). Oficinando com jogos digitais: experiências de aprendizagem inventiva. Curitiba: CRV, 2017. p. 209-227.

MACHADO, A. Novos territórios do documentário. Doc On-line. n. 11, dez. 2011. Disponível em: <http://www. doc.ubi.pt/11/dossier_arlindo_machado.pdf>. Acesso em: 15 abr. 2016.

MATURANA, H. A ontologia da realidade. Organizado por Miriam Graciano, Nelson Vaz e Cristina Magro. Belo Horizonte: UFMG, 1997.

MATURANA, H.; VARELA, F. A árvore do conhecimento: as bases da compreensão humana. São Paulo: Palas Athena, 2001.

MESTRES. Direção: Tiago Fernandes e Marcelo Noms. Porto Alegre: NAVI IPA, 2013. (10min). Disponível em: <https://youtu.be/7jPdh5ofARQ>. Acesso em: 12 nov. 2017.

NANOOK, o Esquimó. Direção: Robert Flaherty. Estados Unidos/França: [s.n.], 1922. (78min). Disponível em: <https://youtu.be/v-dQbuW4kY4>. Acesso em: 12 nov. 2017.

NICHOLS, B. Introdução ao documentário. Campinas: Papirus, 2005.

OITO e Meio. Direção: Federico Fellini. Reino Unido: Cineriz, 1963. (138min).

PASSOS, E; BARROS, R. B. A cartografia como método de pesquisa-intervenção. PASSOS, E., KASTRUP, V., ESCÓSSIA, L. (Orgs.). Pistas do método da cartografia: Pesquisa-intervenção e produção de subjetividade. Porto Alegre: Sulina, 2015. p.17- 31.

PUCCINI, S. Roteiro de Documentário: Da pré-produção à pós-produção. Campinas: Papirus, 2012.

ROUCH, J. O filme etnográfico. In: LABAKI, A. (org.). A verdade de cada um. São Paulo: Cosac Naify, 2015. p. 66-102.

SANTIAGO. Direção: João Moreira Salles. Produção: João Moreira Salles, Maurício Andrade Ramos, Raquel Freire. Rio de Janeiro: Videofilmes, 2007. DVD (107 min).

SEM_ROTEIRO.DOC. Direção: Raphael Oliveira. Porto Alegre: Centro Universitário Metodista IPA, 2013. (18min). Disponível em: <https://youtu.be//3SnzPA1PpA>. Acesso em: 12 nov. 2017.

THOMPSON, E. A mente na vida: biologia, fenomenologia e as ciências da mente. Lisboa: Instituto Piaget, S/D. VARELA, F; THOMPSON, E; ROSCH, E. A mente incorporada: ciências cognitivas e experiência humana. Porto Alegre: Artmed, 2003.

VARELA, F. Conhecer. Ciências Cognitivas: Tendências e Perspectivas. Lisboa: Instituto Piaget, (s/d) 